\title{
Analisis Data Penerimaan Mahasiswa Baru Untuk Meningkatkan Potensi Pemasaran Universitas Menggunakan Business Intelligence (Studi Kasus Universitas XYZ)
}

\author{
Sopian Alviana ${ }^{1}$, Bobi Kurniawan ${ }^{2)}$ \\ Program Studi Teknik Informatika ${ }^{1}$, Program Teknik Elektro ${ }^{2}$ \\ Universitas Komputer Indonesia ${ }^{1,2)}$ \\ sopian.alviana@email.unikom.ac.id ${ }^{1}$, bobi@email.unikom.ac.id ${ }^{2}$
}

\begin{abstract}
ABSTRAK
Kegiatan penerimaan mahasiswa baru merupakan kegiatan yang sangat penting bagi universitas. Seiring berjalannya sistem operasional penerimaan mahasiswa yang ada, maka data penerimaan mahasiswa menjadi bertambah banyak dari tahun ke tahun. Data penerimaan tersebut belum dimanfaatkan oleh pihak universitas dalam pengambilan keputusan strategis, potensi pemasaran, dan pertimbangan undangan jalur penerimaan melalui akademik. Maka, untuk membantu dalam pengolahan data penerimaan mahasiswa baru tersebut, pada penelitian ini dilakukan perancangan dan analisis data penerimaan mahasiswa baru menggunakan tahapan pada business intelligence. Metode yang digunakan pada penelitian ini meliputi tahapan pengambilan data sumber, proses extraction, transform, dan loading (ETL), serta pembuatan grafik data hasil analisis. Dalam pengolahan data penerimaan mahasiswa baru digunakan algoritma time series untuk menganalisis data mahasiswa baru dari tahun ke tahun. Hasil yang didapatkan dalam penelitian ini yaitu menerapkan business intelligence pada data penerimaan mahasiswa baru untuk mendapatkan informasi yang dapat mendukung kebijakan pada tingkat universitas dalam mendukung potensi pemasaran. Informasi yang didapatkan yaitu meliputi sebaran kota dan provinsi asal mahasiswa, program studi dan fakultas pilihan mahasiswa. Dengan analisis dan rancangan pada data penerimaan mahasiswa baru diharapkan dapat membantu mendukung keputusan manajemen di tingkat universitas terkait potensi pemasaran untuk universitas setiap tahun.
\end{abstract}

Kata Kunci : business, intelligence, etl, pmb, akademik.

\section{PENDAHULUAN}

Kegiatan penerimaan mahasiswa baru (PMB) merupakan salah satu kegiatan rutin tahunan sebagai media untuk merekrut calon mahasiswa baru [1]. Universitas XYZ merupakan salah satu universitas di Bandung yang membuka jalur penerimaan mahasiswa baru melalui ujian mandiri dan jalur undangan. Pada pelaksanaanya universitas menggunakan sistem informasi penerimaan mahasiswa baru sebagai operasional untuk mendata mahasiswa baru yang melakukan pendaftaran dan registrasi ulang.

Dengan berjalannya proses tersebut, jumlah data mahasiswa baru dari tahun ke tahun mengalami peningkatan, sehingga semakin banyak data yang harus dikelola. Data PMB tersebut meliputi data asal mahasiswa, data asal sekolah, prodi yang diambil, jenjang yang diambil serta jalur yang digunakan untuk masuk ke universitas.

Saat ini proses PMB di lingkungan Universitas XYZ telah berjalan dengan menggunakan sistem informasi berbasis aplikasi untuk setiap pendaftaran atau registrasi ulang sebagai mahasiswa.

Proses penerimaan mahasiswa baru ini merupakan hal yang sangat penting bagi pihak universitas terutama manajamen kampus dalam hal ini pihak Rektorat. Dengan seiringnya bertambah data penerimaan mahasiswa dari tahun ke tahun yang mengalami peningkatan terkadang membuat data tersebut semakin banyak dan hanya bersifat sebagai transaksional. Sedangkan, pihak manajemen universitas hanya membutuhkan data berupa laporan yang cepat, mudah, dan tidak mengganggu transaksional dengan tujuan untuk mempermudah pihak 
manajemen dalam mengambil keputusan yang strategis terkait dengan penerimaan mahasiswa baru. Maka, dalam hal ini diperlukan sistem yang dapat mendukung keputusan strategis di tingkat universitas. Business Intelligence (BI) merupakan elemen penting dalam pengelolaan modal intelektual dan proses pengambilan keputusan untuk membantu para pimpinan dan manajer meningkatkan kinerja perguruan tinggi [2]. Ika kurniawati menggunakan business intelligence untuk menentukan strategi promosi mahasiswa baru, hasilnya didapatkan strategi promosi bagi calon mahasiswa sesuai dengan program studi yang diminati [1].

Mustafid melakukan penelitian dengan menggunakan sistem business intelligence untuk mendukung pengelolaan program bisnis akademik kearah yang lebih kompetitif melalui sistem perencanaan, pengukuran, dan meningkatkan kinerja berbasis modal intelektual. Modal intelektual perguruan tinggi dideskripsikan berdasarkan sumber daya perguruan tinggi yang dimiliki, agar dalam pengelolaan modal intelektual menjadi lebih optimal. Modal intelektual meliputi modal structural dan manusia [2].

Stephanie Pamela dkk analisa dan desain real time business intelligence menggunakan metode Change Data Capture (CDC) untuk membantu pengambilan keputusan strategis yang membawa dampak peningkatan mutu institusi dan membantu dalam penyusunan boring akreditasi. Proses pembuatan data warehouse meliputi perancangan data warehouse, pengambilan data akademik dari sumber data, proses extraction, transform, loading (ETL), pembuatan cube, dan pembuatan laporan. Proses ETL dilakukan menggunakan pendekatan Change Data Capture (CDC) agar perubahan data dapat dipindahkan secara real-time [3].

Nur Ardista dkk membuat rancang bangun data warehouse untuk pembuatan laporan dan analisis pada data kunjungan pasien rawat jalan rumah sakit Universitas Airlangga. Data warehouse berbasis Online Analytical Processing (OLAP) dapat diterapkan untuk menangani masalah bagian rekam medis RSUA dalam pembuatan laporan. Data warehouse dibangun melalui tujuh tahap yaitu analisis, desain, proses ETL (Extraction, Transformation, dan Loading), penerapan OLAP, uji coba, eksplorasi untuk hasil laporan dan analisis, serta evaluasi [4].

Devriady Pratama melakukan penelitian dengan implementasi data warehouse dan aplikasi dashboard serta proses OLAP guna pelaporan status penjualan. Metodologi substansi untuk perancangan data warehouse akan mengikuti proses dari Ralph Kimball untuk indsutri retail. Hasilnya berupa data warehouse terhadap penjualan lengkap dengan aplikasi pelaporan berbasis web dari proses OLAP dan aplikasi dashboard yang menampilkan perkembangan penjualan sales group dari waktu ke waktu dalam tampilan grafik [5].

Kristiawan nugroho menggunakan time series untuk melakukan prediksi terhadap sesuatu berdasarkan data berkala. Data berkala adalah data yang dikumpulkan dari waktu ke waktu untuk menggambarkan perkembangan suatu kegiatan [7].

Maka dalam penelitian ini bertujuan untuk menghasilkan analisis data pada penerimaan mahasiswa baru dengan proses business intelligence berdasarkan data berkala.yang dapat dijadikan sebagai upaya meningkatkan potensi pemasaran universitas, serta dapat dijadikan rujukan untuk pihak universitas dalam mengambil keputusan strategis terkait penerimaan mahasiswa baru. Proses analisis tersebut melibatkan jumlah data dalam waktu tertentu yang ditampilkan dalam bentuk grafik agar memudahkan dalam pembacaan setiap laporan.

\section{METODE PENELITIAN}

Metode yang digunakan pada penelitian ini mengacu pada tahapan di System Development Life Cycle (SDLC). SDLC merupakan metodologi umum yang digunakan untuk mengembangkan sistem informasi [6]. Metode yang digunakan seperti ditunjukan gambar 1 . 


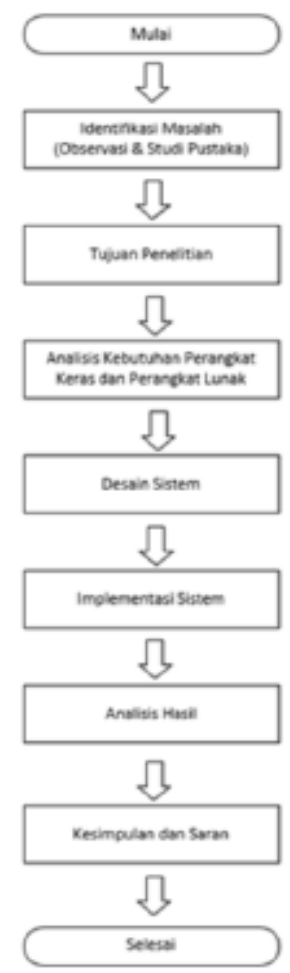

Gambar 1. Metode Penelitian

Tahapan tersebut sejalan dengan tahapan yang yang dilakukan pada proses business intelligence yaitu identifikasi masalah, identifikasi lokasi, merubah data, mengambil data, menyimpan dan memasang aplikasi [8]. Penelitian meliputi pada identifikasi masalah, tujuan penelitian, analisis kebutuhan sistem, desain sistem, implementasi sistem, analisis hasil, serta kesimpulan dan saran.

1. Pada tahapan identifikasi masalah merupakan tahapan dalam proses awal pembangunan data warehouse yaitu mengidentifikasi permasalahan yang timbul pada bagian penerimaan mahasiswa baru. Diantaranya permsalahan data yang semakin bertambah serta belum dimanfaatkannya data tersebut oleh pihak manajemen universitas sebagai kebutuhan dalam mendukung kebijakan strategis.

2. Pada tujuan penelitian menguraikan tujuan yang ingin dicapai terhadap sistem yang dibangun berkaitan dengan analisis data pada bagian penrimaan mahasiswa baru.

3. Analisis kebutuhan sistem merupakan tahapan dalam menganalisa kebutuhan sistem baik secara perangkat keras maupun perangkat lunak. Analisi kebutuhan ini meliputi terhadap aplikasi yang digunakan berbasis web, serta kebutuhan perangkat keras dalam menunjang sistem tersebut. Serta menganalisa kebutuhan untuk proses bisnis yang dapat mendukung kebutuhan promosi universitas.

4. Desain sistem merupakan tahapan mendesain sistem informasi yang dibutuhkan sesuai dengan kebutuhan pada proses bisnis intelijen. Desain meliputi pada desain arsitektur jaringan, dan desain sistem informasi yang digunakan.

5. Implementasi sistem merupakan tahapan pengolahan data dalam sistem informasi terkait dengan data penerimaan mahasiswa baru.

6. Analisis hasil merupakan kegiatan analisis pada data yang ditampilkan oleh sistem dan melakukan Analisa terhadap hasil kebutuhan pada promosi universitas dari grafik data yang disajikan.

7. Kesimpulan dan saran merupakan tahapan dalam mengambil kesimpulan dari sistem yang diterapkan dan memberikan saran terhada perbaikan sistem agar lebih baik.

\section{HASIL PENELITIAN}

1. Analisa proses bisnis yang sedang berjalan Analisa proses bisnis sistem yang berjalan saat ini digunakan untuk mengetahui kebutuhan sistem dan permasalahan yang terjadi. Berdasarkan hasil penelitian didapatkan beberapa prosedur yang berjalan saat ini terhadap penerimaan mahasiswa baru.

a. Calon mahasiswa mendaftar secara online maupun offline.

b. Kemudian mahasiswa mendapatkan kartu ujian.

c. Mahasiswa melaksanakan ujian.

Pada proses tersebut data calon mahasiswa dari tahun ke tahun hanya dijadikan sebagai data transaksional. Para pimpinan hanya menerima jumlah mahasiswa yang mendaftar, sedangkan data penerimaan mahasiswa baru jika diolah mempunyai kebutuhan informasi 
yang sangat penting terhadap kebutuhan promosi universitas.

2. Arsitektur logika datawarehouse

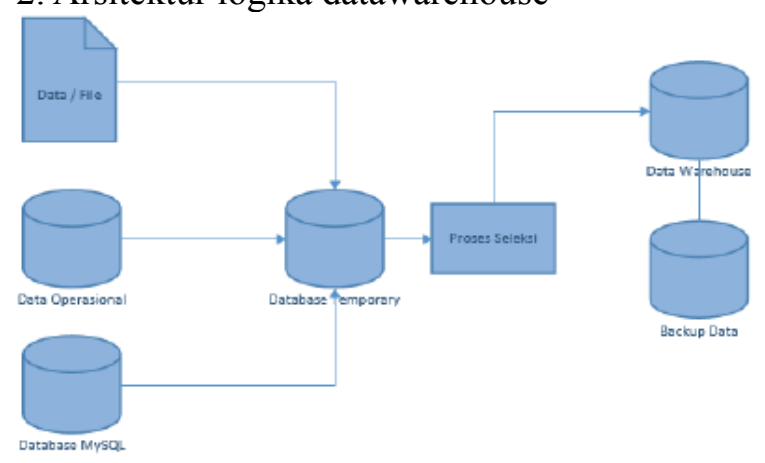

Gambar 2. Arsitektur Logika Data PMB

Gambar 2 menunjukan arsitektur logika data penerimaan mahasiswa baru yang dibutuhkan. Data tersebut terdiri dari beberapa data sumber yang berasal dari beberapa file yang tersimpan pada proses transaksi. Dari kumpulan data tersebut kemudian dilakukan seleksi untuk memilih data yang sesuai untuk dimasukan kedalam data warehouse penerimaan mahasiswa baru.

\section{Arsitektur fisik datawarehouse}

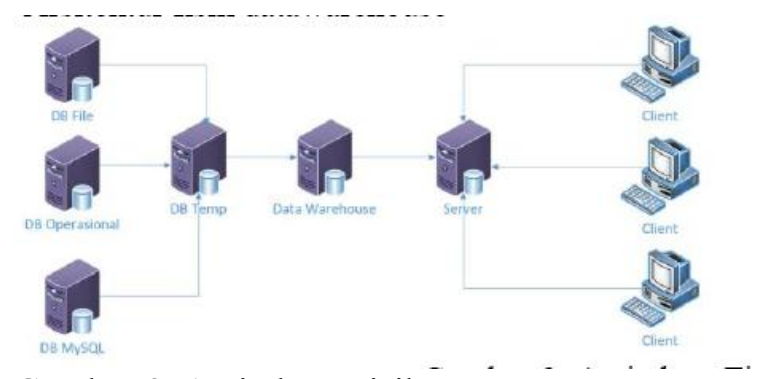

Gambar 3. Arsitektur Fisik Data PMB

Gambar 3 menunjukan arsitektur fisik datawarehouse penerimaan mahasiswa baru. Arsitektur fisik ini meliputi komponen data sumber yang berasal dari bagian keuangan, PMB, dan data operasional penerimaan mahasiswa baru. Temporary database digunakan untuk menampung data dari data sumber dan dijadikan sebagai tempat penampungan data operasional. Datawarehouse merupakan tempat dimana data telah diseleksi dan dipilah untuk dapat dijadikan sebagai laporan kepada pihak universitas yang akan menggunakan sistem.

4. Pemilihan proses bisnis

Setelah rancangan sistem terbentuk, maka dilakukan Analisa terhadap proses bisnis yang akan dijadikan sebagai laporan untuk kebutuhan pihak universitas. Proses bisnis yang dijadikan sebagai bahan laporan untuk pihak universitas terhadap promosi universitas yaitu :

a. Analisa jumlah penerimaan mahasiswa baru.

b. Analisa program studi pilihan.

c. Analisa sebaran daerah mahasiswa dari tahun ke tahun.

d. Analisa mahasiswa berdasarkan fakultas yang dipilih.

\section{PEMBAHASAN}

Pada tahapan ini merupakan hasil dari implementasi analisis data penerimaan mahasiswa baru yang ditampilkan dalam bentuk sistem informasi. Sistem informasi yang ditampilkan meliputi tampilan login sistem, halaman dashboard utama, serta halaman informasi penerimaan mahasiswa baru yang dikelompokan berdasarkan kota asal mahasiswa, provinsi asal mahasiswa, jurusan yang diminati, serta fakultas yang diminati oleh para mahasiswa baru. Berikut hasil implementasi analisis data dengan menggunakan bisnis intellijen.

\section{Desain Sistem}

Pada hasil implemntasi sistem digunakan sistem informasi berbasis web yang terdiri pada halaman login, tampilan utama sistem, dan informasi data penerimaan mahasiswa baru.

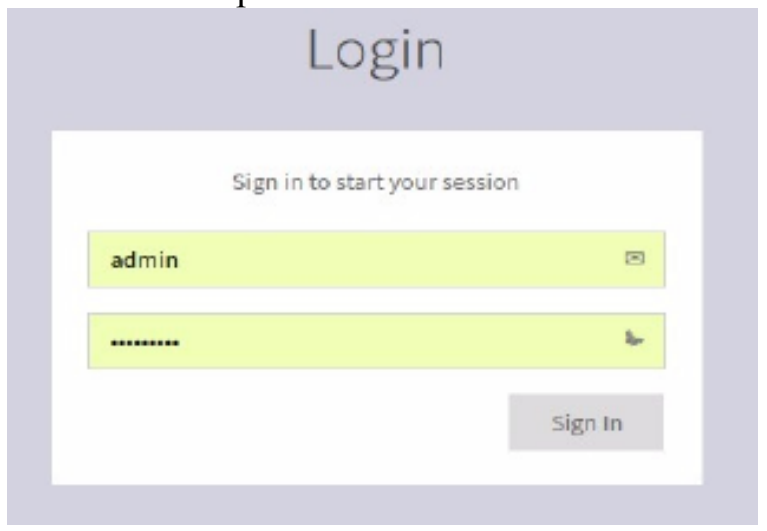

Gambar 4. Halaman Login Sistem 
Gambar 4 menunjukan tampilan halaman login sistem yang dibangun, terdiri dari username dan password.

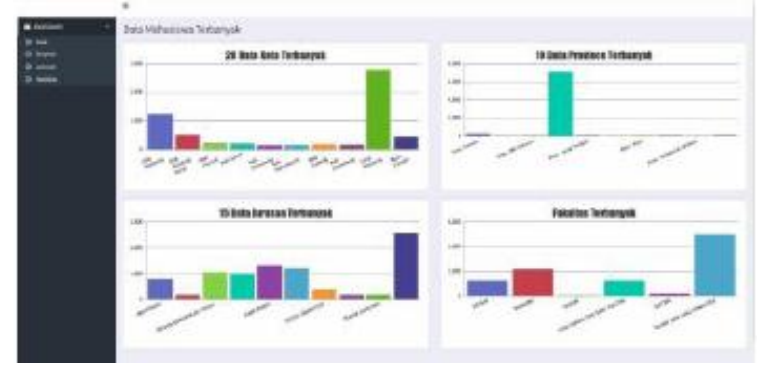

Gambar 5. Tampilan Utama Dashboard

Gambar 5 menunjukan tampilan utama dashboard sistem informasi yang meliputi grafik data kota terbanyak mahasiswa baru, provinsi terbanyak, jurusan favorit yang diminati, serta fakultas favorit yang diminati.

2. Hasil Analisa data penerimaan mahasiswa baru terhadap kota mahasiswa

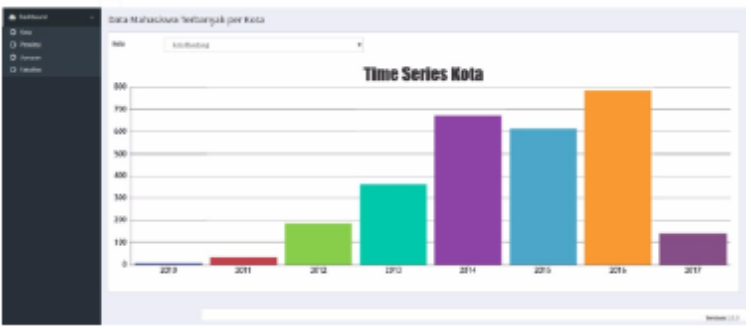

Gambar 6. Hasil Kota Mahasiswa Baru

Gambar 6 menunjukan hasil Analisa data berdasarkan waktu penerimaan mahasiswa baru terhadap kota asal mahasiswa. Dari hasil tersebut terlihat bahwa asal kota yang mendominasi terhadap perguruan tinggi $\mathrm{XYZ}$ yaitu mendaftar dari kota bandung.

3. Hasil Analisa data penerimaan mahasiswa baru terhadap provinsi asal mahasiswa

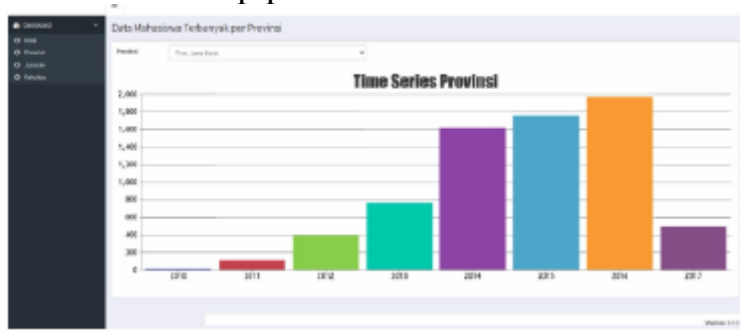

Gambar 7. Hasil Provinsi Mahasiswa Baru
Gambar 7 menunjukan hasil Analisa data berdasarkan waktu penerimaan mahasiswa baru terhadap provinsi asal mahasiswa. Dari hasil tersebut terlihat bahwa asal provinsi yang mendominasi terhadap perguruan tinggi $\mathrm{XYZ}$ yaitu mendaftar dari provinsi jawa barat.

4. Hasil Analisa data penerimaan mahasiwa baru terhadap program studi

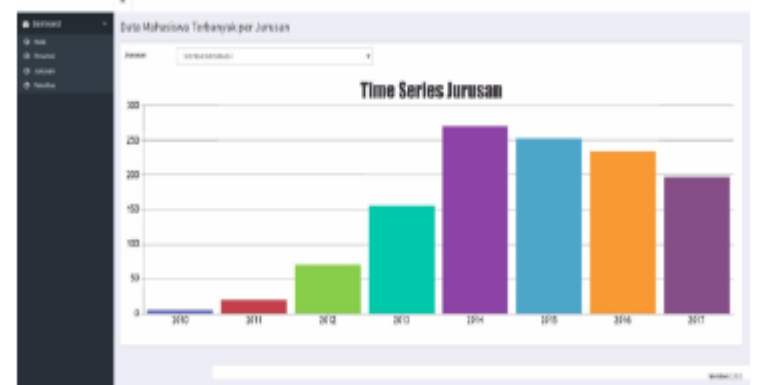

Gambar 8. Hasil Program Studi Pilihan

Gambar 8 menunjukan hasil Analisa data berdasarkan waktu penerimaan mahasiswa baru terhadap program studi pilihan mahasiswa. Dari hasil tersebut terlihat bahwa program studi yang paling banyak diminati oleh mahasiswa adalah program studi Teknik informatika, sistem informasi, manajemen, ilmu komunikasi, dan desain komunikasi visual.

5. Hasil Analisa data penerimaan mahasiswa baru terhadap fakultas

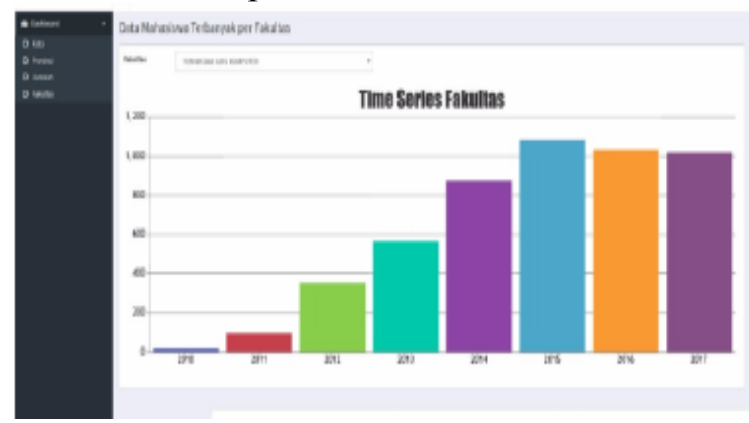

Gambar 9. Hasil Fakultas Pilihan

Gambar 9 menunjukan hasil Analisa data berdasarkan waktu penerimaan mahasiswa baru terhadap fakultas pilihan mahasiswa. Dari hasil tersebut terlihat bahwa fakultas yang paling banyak diminati oleh mahasiswa adalah fakultas Teknik, ekonomi, dan desain. 


\section{PENUTUP}

Setelah melakukan analisis data penerimaan mahasiswa baru dengan proses bisnis intellijen didapatkan kesimpulan yaitu :

1. Dengan adanya sistem informasi analisis data penerimaan mahasiswa baru diharapkan dapat membantu pihak universitas untuk dapat meningkatkan promosi universitas.

2. Mempermudah pihak universitas untuk menyebarkan promosi universitas berdasarkan daerah.

3. Pihak universitas dapat melihat program studi mana yang diminati oleh para calon mahasiswa.

4. Potensi fakultas dan program studi Teknik masih menjadi pilihan favorit bagi setiap calon mahasiswa.

\section{DAFTAR PUSTAKA}

[1]. Kurniawati, I., Indrajit, R. E., \& Fauzi, M. (2017). Peran Bussines Intelligence Dalam Menentukan Strategi Promosi Penerimaan Mahasiswa Baru. IKRAITHINFORMATIKA, 1(2), 70-79.

[2]. Mustafid, M. (2016). Sistem business intelligence untuk mendukung perguruan tinggi yang kompetitif. Jurnal Sistem Informasi Bisnis, 3(1), 18-24.

[3]. Adithama, S. P., Wisnubhadra, I., \& Sinaga, B. L. (2013). Analisis Dan Desain Realtime Business Intelligence Untuk Subjek Kegiatan Akademik Pada Universitas Menggunakan Change Data Capture. In Seminar Nasional Teknologi Informasi dan Komunikasi (pp. 87-95).

[4]. Ardista, N., Purbandini, P., \& Taufik, T. (2017). Rancang Bangun Data Warehouse Untuk Pembuatan Laporan dan Analisis pada Data Kunjungan Pasien Rawat Jalan Rumah Sakit Universitas Airlangga Berbasis Online Analytical Processing (OLAP). Journal of Information Systems Engineering and Business Intelligence, 3(1), 40-51.

[5]. D. Pratama, "Implementasi Datawarehouse Dan Business Intelligence Untuk
Memonitor Penjualan Sales Group : Studi Kasus Pada PT. XYZ," 2013

[6]. Susanto, R., \& Andriana, A. D. (2016). Perbandingan Model Waterfall dan Prototyping untuk Pengembangan Sistem Informasi. Majalah Ilmiah UNIKOM, 14(1).

[7]. Nugroho, K. (2016). Model Analisis Prediksi Menggunakan Metode Fuzzy Time Series. INFOKAM, 12(1).

[8]. Imelda, "Business Intelligence," Majalah Ilmiah UNIKOM, vol. 11, no. 1, pp. 111$121,2010$.

[9]. D. Dharmayanti, A. M. Bachtiar dan A. Heryandi, "Pemodelan Data Warehouse Pada Jurusan Teknik Informatika UNIKOM," 2012.

[10].Ismiati, M. B., Permanasari, A. E., \& Hidayah, I. (2014). Analisis Data Time Series Korban Dbd di Kota Palembang Untuk Mendapatkan Trend dalam Melakukan Forecasting. SEMNASTEKNOMEDIA ONLINE, 2(1), 2-02. 